\title{
Premature introduction of foods and beverages in Guatemalan infants: A comparative perspective across geographic zones
}

\author{
Noel W. Solomons, María José Soto-Méndez, Elena Diaz Ruíz and Marieke Vossenaar* \\ Center for Studies of Sensory Impairment, Aging and Metabolism (CeSSIAM), Guatemala City, Guatemala.
}

Accepted 5 September, 2012

\begin{abstract}
The objective of the current analysis was to compare the pattern of age-of-introduction of commonly consumed complementary foods in the western highlands with what has been reported from the central highlands of Guatemala. Age-of-introduction of 10 sentinel foods was queried by means of structured face-to-face interviews in mothers of 6 to 11 months old infants living in Quetzaltenango $(n=114)$. The mean age-of-introduction was earlier in the metropolitan Quetzaltenango series than in both of the central highland locations, rural and urban. We concluded that different patterns of early introduction of food and beverage items contribute to the precocious occurrence of mixed feeding (MF) in the first semester of infancy in distinct regions of Guatemala.
\end{abstract}

Key words: Complementary foods, self-reported, infant nutrition, Guatemala.

\section{INTRODUCTION}

The World Health Organization (WHO, 2003) recommended as basic infant feeding: "exclusive breast-feeding for 6 months and continued breastfeeding up to 2 years of age or beyond". Any violation of exclusivity of breastfeeding with introduction of water based liquids converts that pattern to one of partial breastfeeding (PBF). Nevertheless, both exclusive breastfeeding (EBF) and PBF constitute a state of "full breastfeeding" according to the WHO criteria (WHO, 2003). It is, however, the introduction of foods and complex beverages which converts the pattern to one of mixed feeding (MF). MF is considered potentially detrimental to the health and nutrition of infants because of the increased risk of gastrointestinal infection (Jones et al.,

${ }^{\star}$ Corresponding author. E-mail: mvossenaar@hotmail.com or cessiam@guate.net.gt. Tel/Fax: +502 24733942.

Abbreviations: EBF, exclusive breastfeeding; CeSSIAM, center for studies of sensory impairment, aging and metabolism; MF, mixed feeding; PBF, partial breastfeeding; WHO, world health organization.
2003; Kramer and Kakuma, 2009).A series of studies in a rural village in the central highlands (Campos et al., 2010; Soto-Méndez et al., 2012) and a poor settlement in Guatemala City (Hernández et al., 2011; Soto-Méndez et al., 2012) revealed high rates of premature introduction of foods or beverages, that is, before 6 months of age. In these two settings, moreover, retrospective inquiry as to the age at introduction of 10 sentinel foods was conducted in Guatemala and reported in an original research report by Soto-Méndez et al., (2012). The same battery of sentinel items was included in our crosssectional study among infants and toddlers in the western highlands, and additional questions were included relating the exact age-of-introduction of foods other than breast milk, such as water-based drinks, infant formula and other foods. In Guatemala, there is little understanding of exactly which practices first violate adherence to EBF during the first semester of life. The objective of the current analysis was to compare the pattern of age-of-introduction of commonly consumed complementary foods in the western highlands with what has been reported from two areas in the central highlands of Guatemala. 


\section{MATERIALS AND METHODS}

\section{Study population}

This survey is part of a study that was conducted in the highlands of Guatemala in Quetzaltenango (latitude 14.83, longitude -91.52), the second most important city of the country and in the nearby suburb of La Esperanza (latitude 14.87, longitude -91.56). Mothers visiting the local public health centers for vaccinations, routine check-ups, or illness were recruited as mother-infant dyads into the study. The mothers ranged in age from 15 to 44 years, mean $26 \pm 6$ years; $41 \%$ were classified as Maya indigenous by their typical garments, with the remainder considered to be non-indigenous. Exclusion criteria were: 1) pre-mature birth (defined as born more than 4 weeks pre-term); 2) had siblings who were already participants; 3 ) had congenital anomalies or chronic illness; and 4) were unwilling to sign the study consent form. The population sample of this subanalysis was infants aged between 6 and 11 months. Enrollment and selection resulted in a group of 114 infants, 53 boys and 61 girls with a mean age of $8 \pm 2$ months. A larger number of infants were recruited in the urban area of Quetzaltenango $(n=65)$ than in the semi-urban area of La Esperanza $(n=49)$. The study recruitment period was from February to October, 2011.

Ethical approval was obtained from the Human Subjects Committee of the Center for Studies of Sensory Impairment, Aging and Metabolism (CeSSIAM) and the study confirms to the provisions of the Declaration of Helsinki in 1995 (as revised in Edinburgh, 2000). The study protocol was approved by the local authorities of the Guatemala Health Ministry. The procedures and privacy issues of the study were explained and informed consent was obtained from all mothers.

\section{Data collection}

A single face-to-face interview using a structured data collection tool designed to evaluate dietary intake and morbidity in young children was administered. A recall of feeding practices since birth was collected. Ever having offered formula milk, water-based drinks other than breast milk, foods and ritual fluids was queried as a 'yes' or 'no' question. Ritual fluids, locally known as "agüitas", are herbal infusions and rice water. If affirmative, the mother was asked the age-of-introduction of these four items as an open-ended question. Thereafter, age-of-introduction of 10 pre-determined commonly consumed complementary foods (Incaparina $\AA^{\circledR}$, oatmeal, rice, fruits, vegetables, white rolls, sweet rolls, baby food in jars, potatoes and coffee) was queried by means of structured interviews. Mothers were asked to report the age of the infant at which each item was introduced, if at all. The 10 foods queried were chosen by experienced field investigators and were not the foods most likely to be introduced earlier or later, nor most commonly consumed by young Guatemalan infants.

\section{Data analysis}

The average reported age of infant at introduction of the 10 predetermined foods and the proportion of children who were offered these foods before 6 months of age were calculated for the pooled sample. The results of the current analysis were compared to finding of previous studies in Central Guatemala and published elsewhere. The first study was conducted in urban mothers and infants attending a health care centre in the district of "Centro America" in Zone 7 of Guatemala City (latitude 14.64, longitude 90.55). The second study was conducted in the rural village of Santo Domingo Xenacoj, located in the central highlands of
Guatemala (latitude 14.68, longitude -90.70). The three study areas are shown in Figure 1. Paired t-test comparisons between the urban area of Quetzaltenango in the western highlands against both Guatemala City and the rural area of Xenacoj were used to compare mean reported age-of-introduction of the 10 foods queried and rates of premature introduction (that is, before 6 months of age).

\section{RESULTS AND DISCUSSION}

\section{Profile of early introduction of non-breast milk foods and drinks into infants' diets in Quetzaltenango}

A general perspective on the timing of introduction of different elements to the infant diets can be gained from the response of the mothers to queries in the questionnaire. At the time of interview in the second semester of life, the vast majority of infants had already consumed ritual fluids $(80 \%)$, water-based drinks other than breast milk (68\%), milk formula (54\%) and foods (67\%). Among consumers, the median age-of-introduction was 14 weeks (range 0 to 41 weeks), 10 weeks (range 0 to 41 weeks), 0 weeks (range 0 to 54 weeks) and 25 weeks (range 5 to 36 weeks) for ritual fluids, water-based drinks, formula and foods, respectively. Almost all infants were introduced to ritual fluids (84\%), water-based drinks $(83 \%)$, formula $(85 \%)$ prematurely, that is, before 6 months of age. Approximately half the infants (45\%) only commenced eating foods in the second semester of life, as recommended by WHO (2003).

Guatemala was one of the settings that facilitated the description of "weanling diarrhea," the epidemiological association of increased occurrence of gastrointestinal infections with the introduction of foods other than human milk (Gordon et al., 1963). Although maternal milk has protective immunological properties, Victora et al. (1987) showed that they could not resist the food-borne microbes associated with the onset of mixed feeding. These are among the considerations leading the WHO strongly to urge women to breastfeed their babies exclusively throughout the first semester of life (WHO, 2003, Kramer and Kakuma, 2009). The findings from our interviews within this sample demonstrate poor adherence to exclusivity of breastfeeding; the resultant mixedfeeding exposes the child to early onset of intestinal infections (Golding et al., 1997; Gribble, 2011), and there is definitive or suggestive evidence for increased life-time risk of other conditions (allergies, obesity, cardiovascular disease, autoimmune illnesses) associated with shorter and less intense breastfeeding (Turck, 2007; Dorea, 2009; Fewtrell, 2011; Owen et al. , 2011).

\section{Age at introduction of sentinel foods}

As shown in Table 1, for each of the 10 sentinel items, the mean age-of-introduction is earlier in the metropolitan 


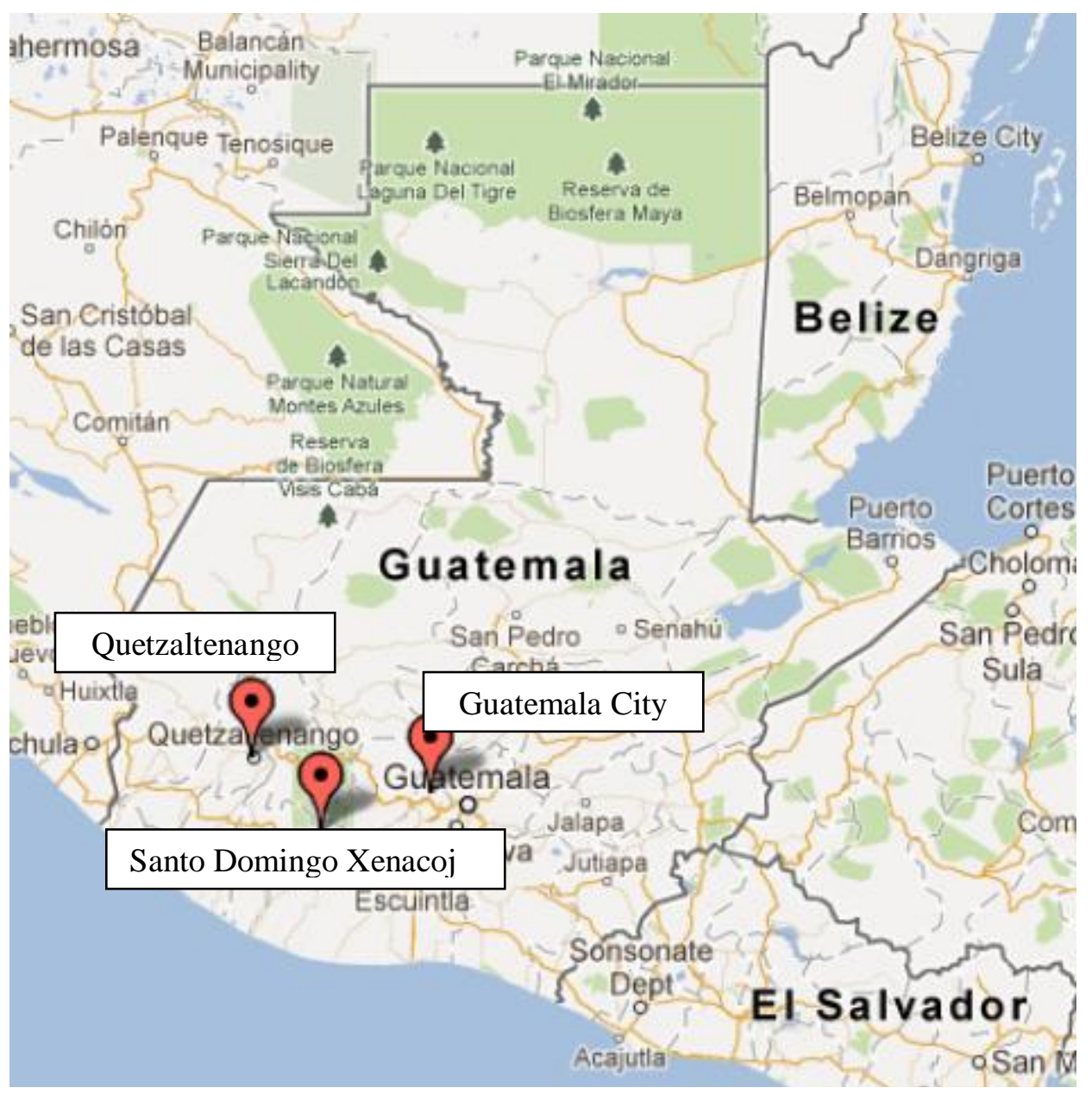

Figure 1. Map of Guatemala showing the three study areas.

Table 1. Average reported age of infant at introduction of 10 pre-determined commonly consumed complementary foods listed per residential area.

\begin{tabular}{lccc}
\hline \multirow{2}{*}{ Food item } & \multicolumn{2}{c}{ Average reported age of infant at introduction of complementary food listed (mo) } \\
\cline { 2 - 4 } & $\begin{array}{c}\text { Urban sample of } \\
\text { Quetzaltenango }(\mathbf{n}=\mathbf{1 1 4})\end{array}$ & $\begin{array}{c}\text { Urban sample of } \\
\text { Guatemala City }(\mathbf{n}=\mathbf{6 4})^{1}\end{array}$ & $\begin{array}{c}\text { Rural sample of Santo } \\
\text { Domingo Xenacoj }(\mathbf{n}=\mathbf{5 0})^{1}\end{array}$ \\
\hline Vegetables & $5.8 \pm 1.1(n=99)$ & $6.5 \pm 1.2(n=59)$ & $6.6 \pm 1.2(n=44)$ \\
Fruits & $6.2 \pm 1.5(n=94)$ & $6.7 \pm 1.6(n=58)$ & $6.9 \pm 1.5(n=35)$ \\
Incaparina & $5.8 \pm 1.6(n=78)$ & $6.9 \pm 2.0(n=33)$ & $6.7 \pm 1.5(n=36)$ \\
Potatoes & $6.0 \pm 1.3(n=87)$ & $6.8 \pm 1.5(n=53)$ & $6.6 \pm 1.3(n=46)$ \\
Baby food in jar & $5.6 \pm 1.2(n=54)$ & $6.2 \pm 1.4(n=35)$ & $6.3 \pm 1.2(n=16)$ \\
Sweet Rolls & $6.2 \pm 1.5(n=76)$ & $6.9 \pm 1.4(n=38)$ & $6.9 \pm 1.3(n=17)$ \\
Oatmeal & $5.9 \pm 1.7(n=50)$ & $7.1 \pm 2.2(n=29)$ & $6.7 \pm 1.6(n=34)$ \\
White Rolls & $6.2 \pm 1.4(n=57)$ & $7.3 \pm 1.6(n=26)$ & $6.9 \pm 1.2(n=40)$ \\
Rice & $6.2 \pm 1.6(n=63)$ & $6.9 \pm 1.9(n=41)$ & $6.9 \pm 1.2(n=39)$ \\
Coffee & $6.7 \pm 1.8(n=43)$ & $7.0 \pm 1.8(n=32)$ & $6.7 \pm 1.1(n=29)$ \\
\hline
\end{tabular}

Values are mean \pm SD for participants who reported having introduced the given food item. ${ }^{1}$ Data previously presented by SotoMéndez. 
Table 2. Proportion of children who were offered 10 pre-determined commonly consumed complementary foods before 6 months of age.

\begin{tabular}{|c|c|c|c|c|c|c|}
\hline \multirow[b]{3}{*}{ Food item } & \multicolumn{6}{|c|}{ Proportion (\%) of children offered these foods before 6 mo } \\
\hline & \multicolumn{3}{|c|}{ Among consumers only } & \multicolumn{3}{|c|}{ Entire sample } \\
\hline & $\begin{array}{l}\text { Urban sample of } \\
\text { Quetzaltenango }\end{array}$ & $\begin{array}{l}\text { Urban sample of } \\
\text { Guatemala City }\end{array}$ & $\begin{array}{l}\text { Rural sample of Santo } \\
\text { Domingo Xenacoj }\end{array}$ & $\begin{array}{c}\text { Urban sample of } \\
\text { Quetzaltenango } \\
\quad(n=114)\end{array}$ & $\begin{array}{c}\text { Urban sample of } \\
\text { Guatemala City } \\
(n=64)\end{array}$ & $\begin{array}{c}\text { Rural sample of Santo } \\
\text { Domingo Xenacoj } \\
(n=50)\end{array}$ \\
\hline Vegetables & 34 & 16 & 19 & 30 & 14 & 17 \\
\hline Fruits & 34 & 20 & 21 & 28 & 14 & 19 \\
\hline Incaparina® & 33 & 17 & 21 & 23 & 12 & 11 \\
\hline Baby food in jar & 37 & 31 & 26 & 18 & 10 & 14 \\
\hline Sweet rolls & 23 & 18 & 13 & 16 & 6 & 8 \\
\hline Oatmeal & 28 & 18 & 21 & 12 & 12 & 9 \\
\hline White rolls & 23 & 13 & 12 & 11 & 10 & 5 \\
\hline Rice & 19 & 10 & 20 & 11 & 8 & 13 \\
\hline Coffee & 23 & 14 & 16 & 9 & 8 & 8 \\
\hline P-value & & $0.001^{1}$ & $<0.001^{2}$ & & $0.012^{1}$ & $0.003^{2}$ \\
\hline
\end{tabular}

P-value for the difference in rates of premature introduction of the 10 foods queried between the urban sample of Quetzaltenango and urban sample of Guatemala City using dependent $t$-test analysis. P-value for the difference in rates of premature introduction of the 10 foods queried between the urban sample of Quetzaltenango and rural sample of Santo Domingo Xenacoj using dependent $t$ test analysis.

Quetzaltenango series than in both the central highland locations, rural and urban. The only exception is coffee, which was introduced at a mean age of 6.7 months in both Quetzaltenango and Santo Domingo Xenacoj. As such, it is not surprising that the paired $t$-test comparisons of western, urban highlands against both the rural area of Xenacoj $(p=0.006)$ and Guatemala City $(p<0.001)$ were highly significant.

The percentage of eventual consumers who had been introduced to the various items in the three geographic settings before 6 months is shown in Table 2. For the western highlands, for instance, vegetables and fruits before 6 months was 30 and $28 \%$, respectively. At the other end of the spectrum, the first presentation of rice and coffee occurred before reaching 6 months of age in only 11 and $9 \%$ of eventual consumers in the western highlands' metropolitan site. Moreover, when the series of percentage of consumers who first consumed the items before 6 months of age were compared between the western area of Quetzaltenango and central Guatemalan locations, as shown in Table 2, the rates were universally higher in the western area than either the eastern urban $(p=0.001)$ or rural area $(p<$ 0.001).

Of further interest, regarding a larger cultural consensus about early feeding across the whole nation of Guatemala is the general similarity in all sites in the items of early introduction, for example, baby food in a jar, vegetables and fruits, and those of later presentation to young children, for example, white rolls, rice and coffee. It is interesting that two forms of gruels - Incaparina ${ }^{\circledR}$ and oatmeal - are in the earliest bracket in the western region and introduced relatively later in the sequence in the eastern sites.

Different patterns of early introduction of food and beverage items contribute to the precocious occurrence of MF in the first semester of infancy in distinct regions of Guatemala. There is a trend towards earlier introduction of foods in the western highlands than in Guatemala City and the rural area in eastern Guatemala. 


\section{STRENGTHS AND LIMITATIONS}

The strengths of this study are its linkage to a previous set of inquiries using identical questionnaire language and item list, and the interval of retrospective memory identical, as well, with questioning occurring in the $7^{\text {th }}$ through the $12^{\text {th }}$ months of infant life. Imbedded in this is a potential weakness as different field teams conducted the interviews in the central highlands studies; without standardization with the former. Some subtle signals could have systematically affected the clues for responses to the same questions given by the present interviewers. The sample of our study is not necessarily representative of the Quetzaltenango area. Children were recruited from the vaccination site of the health centres, and thus probably had better access to health care than others. Furthermore, some misclassification of ethnicity based on clothing may have occurred given that Mayan indigenous women sometimes wear western clothes. An admitted limitation of the exercise from its origins (SotoMéndez et al., 2012), moreover, is that the selection of edible items was arbitrarily derived from the notions of the original field team. On the positive side of the ledger, however, is the homology of pattern of earlier and later introduced foods, which provides construct validity to the relative response pattern of the Quetzaltenango interviewees.

\section{Conclusion}

The aforementioned caveats notwithstanding, it appears that women from a metropolitan region in the interior of Guatemala introduce the selected foods earlier in life than their homologues in the nation's capital and in a Mayan village near the capital. Early MF, that is, the introduction of non-breast milk items to the diet before the completion of the 6 months of age, is revealed as a widespread practice among the mothers of this sample in Quetzaltenango.

\section{ACKNOWLEDGEMENTS}

We thank our collaborator Colleen Doak, the nutritionists who interviewed the mothers (Claudia Alejandra Maldonado, Deborah Fuentes, Elena María Díaz Ruiz, and Gabriela Montenegro-Bethancourt); the students who helped recruit participants and enter data (Jeniece Alvey, Natasha Irving, Lydia Kim, Linda Oyesiku, Oscar Padilla, Leonie Peters, Marieke Reurings, Ilse van Beusekom, and Robine van der Starre); and the staff of the Quetzaltenango health clinic. Mostly, we thank the participants of the study for their collaboration. Financial support was obtained from Sight and Life, Basel,
Switzerland and the Hildegard Grunow Foundation of Munich, Germany.

\section{REFERENCES}

Campos R, Hernández L, Soto- Méndez MJ, Vossenaar M, Solomons NW (2010). Contribution of complementary food nutrients to estimated total nutrient intakes for rural Guatemalan infants in the second semester of life. Asia Pac. J. Clin. Nutr. 19:481-490.

Dorea JG (2009). Breastfeeding is an essential complement to vaccination. Acta. Paediatr. 98:1244-1250.

Fewtrell MS (2011). Breast-feeding and later risk of CVD and obesity: evidence from randomised trials. Proc. Nutr. Soc. 70:472-477.

Golding J, Emmett PM, Rogers IS (1997). Gastroenteritis, diarrhoea and breast feeding. Early Hum. Dev. 49:S83-103.

Gordon JE, Chitkara ID, Wyon JB (1963). Weanling diarrhea. Am. J. Med. Sci. 245:345-377.

Gribble KD (2011). Mechanisms behind breastmilk's protection against, and artificial baby milk's facilitation of diarrhoeal illness. Breastfeed. Rev. 19:19-26.

Hernández L, Campos R, Enneman A, Palma AV, Soto- Méndez MJ, Vossenaar M, Solomons NW (2011). Contribution of complementary food nutrients to estimated total nutrient intakes for urban Guatemalan infants in the second semester of life. Asia Pac J. Clin. Nutr. 20:572-583.

Jones G, Steketee RW, Black RE, Bhutta ZA, Morris SS (2003). How many child deaths can we prevent this year? Lancet 362:65-71.

Kramer MS, Kakuma R (2009). Optimal duration of exclusive breastfeeding (Review). The Cochrane Collaboration.

Owen CG, Whincup PH, Cook DG (2011). Breast-feeding and cardiovascular risk factors and outcomes in later life: evidence from epidemiology studies. Proc. Nutr. Soc. 70:478-484.

Soto- Méndez MJ, Campos R, Hernández L, Vossenaar M, Solomons N (2012). Reproducibility regarding the age of introduction of complementary foods to infants as self-reported by urban and rural low-income mothers in Guatemala. J. Public Health Epidemiol. 3:410418.

Turck D (2007). Later effects of breastfeeding practice: the evidence. Nestle Nutr. Workshop Ser. Pediatr. Program 60:31-39.

Victora CG, Smith PG, Vaughan JP, Nobre LC, Lombardi C, Teixeira AM, Fuchs SM, Moreira LB, Gigante LP, Barros FC (1987). Evidence for protection by breast-feeding against infant deaths from infectious diseases in Brazil. Lancet 2:319-322.

WHO (2003). Global strategy for infant and young child feeding. Geneva: World Health Organization. 